\title{
Spinal Cord Editor's Page November 2006
}

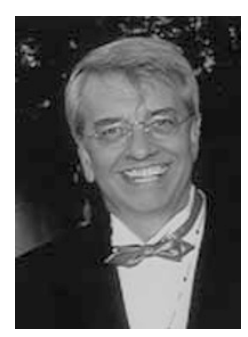

Dear All,

The Spinal Cord Editorial Office has been busy over the past month. As part of our ongoing efforts to improve the service we provide to our readership, new Instructions to Authors have been introduced. These include precise instructions on the article types that will be accepted for publication in Spinal Cord, including stricter guidelines on article lengths. Manuscripts that adhere to these new guidelines will soon start to be published online and in print. Please visit http://mts-sc.nature.com to read the new instructions and submit your article online.

The November issue of Spinal Cord is packed full of important and interesting information:

This month's review article provides a critical evaluation of the published literature on the physical capacity of patients in wheelchairs after spinal cord injury, and draws some valuable conclusions.

Two manuscripts on animal experiments have been included: one evaluates electrophysiological changes in isolated spinal cord white matter in response to oxygen deprivation; the other looks into the protective effects of the extract of Ginkgo Biloba on nerve cells after spinal cord injury.

The first clinical article describes the demographics of a multicenter prospective cohort study on restoration of mobility in spinal cord injury rehabilitation, carried out in The Netherlands. We all know that informal carers of spinal cord patients are an important, yet often neglected, group - the second clinical manuscript in this issue addresses the important issue of leisure satisfaction and psychiatric morbidity of informal carers. A third clinical study examines lower extremity skeletal muscle function in the case of incomplete spinal cord injury.

Finally, three case reports describe unusual clinical cases.

We hope you enjoy this issue of Spinal Cord, and welcome your continued suggestions for the journal.

Spinal Cord (2006) 44, 641. doi:10.1038/sj.sc.3101994

J-J Wyndaele

Editor-in-Chief

E-mail: Spinalcord@uza.be 